\title{
Heterologous expression of the bacteriocin mesentericin Y105 using the dedicated transport system and the general secretion pathway
}

\author{
Franck Biet, ${ }^{1}$ Jean Marc Berjeaud, ${ }^{1}$ Randy W. Worobo, ${ }^{1} \dagger$ \\ Yves Cenatiempo' and Christophe Fremaux ${ }^{1,2}$
}

Author for correspondence: Christophe Fremaux. Tel: +33 5494540 06. Fax: + 33549453503 .
e-mail: christophe.fremaux@cri.univ-poitiers.fr

1 Institut de Biologie Moléculaire et d'Ingénierie Génétique, CNRS-ESA 6031, Université de Poitiers, 40 avenue du Recteur Pineau, 86022

Poitiers Cedex, France

2 Texel, groupe RhônePoulenc, ZA de Buxières BP 10, 86220 Dangé SaintRomain, France

\begin{abstract}
Two different $\mathbf{N}$-terminal extensions have been identified within class II bacteriocin precursors. The first one is a two-glycine-type leader peptide associated with a dedicated ATP-binding cassette transporter. The second is a signal peptide which directs the bacteriocin precursor to the general secretion machinery. Mesentericin Y105 is a class II anti-Listeria bacteriocin produced by Leuconostoc mesenteroides Y105 via a dedicated transport system (DTS). To investigate heterologous expression systems capable of producing mesentericin Y105 in various hosts, two different secretion vectors were constructed. One of them, containing the mesentericin Y105 structural gene fused to the segment encoding the divergicin A signal peptide, was introduced into Escherichia coli, Leuconostoc subsp. and Lactococcus subsp. In E. coli, mesentericin Y105 production was linked to a putative periplasmic toxicity. To take advantage of this secretion system, the mesentericin Y105 precursor was also produced in E. coli. It was demonstrated that this pre-bacteriocin exhibited some antagonistic activity against Listeria. To allow for a comparison between the two different transport systems, mesentericin Y105 production using the vector containing the mesentericin Y105 structural gene and its DTS transporter operon was examined. The production of mesentericin Y105 was monitored by a new fast purification method followed by MS analysis. It was shown that, in Leuconostoc, the production of mesentericin Y105 is enhanced via the DTS compared to the general secretion pathway.
\end{abstract}

Keywords: bacteriocin, secretion, heterologous expression, lactic acid bacteria

\section{INTRODUCTION}

Bacteriocins are proteinaceous compounds produced by many lactic acid bacteria (LAB) that typically inhibit the growth of closely related species. They were classified into four classes by Klaenhammer (1993). Class II bacteriocins produced by $\mathrm{LAB}$ constitute the largest group so far characterized. They consist of small heatstable peptides possessing an $\mathrm{N}$-terminal extension of

†Present address: Cornell University, Department of Food Science and Technology, New York State Agricultural Experiment Station (NYSAES), Geneva, NY 14456-0462, USA.

Abbreviations: DTS, dedicated transport system; GSP, general secretion pathway; LAB, lactic acid bacteria.
18-24 residues that contains a conserved Gly-Gly processing site (positions -2 and -1 ). It has been shown that most of these class II bacteriocins are exported (Stoddard et al., 1992; Marugg et al., 1992; Bukhtiyarova et al., 1994; Axelsson \& Holck, 1995; van Belkum \& Stiles, 1995; van Belkum et al., 1997) by at least two membrane-bound proteins that form their dedicated transport system (DTS). One of the two proteins belongs to the family of the ATP-dependent transporters (Higgins, 1992). It was demonstrated that the cleavage of the $\mathrm{N}$-terminal extension of the bacteriocin occurred concomitantly to the export of the peptide through the cytoplasmic membrane (Håvarstein et al., 1995). The other protein bears a still unknown function but is postulated to be an accessory protein. It 
is anchored to the membrane by its hydrophobic $\mathrm{N}$ terminus (Franke et al., 1996). Worobo et al. (1995) and Leer et al. (1995) described two new bacteriocins from $\mathrm{LAB}$, divergicin $\mathrm{A}$ and acidocin $\mathrm{B}$, respectively, which are exported by the general secretion pathway (GSP). Indeed, divergicin A and acidocin B are encoded as precursors bearing a signal peptide.

Because of the potential use of bacteriocins as food preservatives and because most industrial strains do not produce such antagonistic peptides, interest in the heterologous expression of class II bacteriocins is rapidly growing. However, most of these bacteriocins display a narrow spectrum of activity. Therefore, it may be possible to design strains that are capable of producing multiple bacteriocins targeting various species. Such an approach will require a large amount of genetic material. Indeed, the production of each bacteriocin requires the cloning of at least four genes, including the bacteriocin structural gene and its immunity gene in addition to the two genes encoding the DTS. Thus, the use of the GSP for the production of bacteriocins or the use of a single DTS for the transport of multiple bacteriocins are promising approaches. Worobo et al. (1995) and McCormick et al. (1996) showed that a protein or a peptide fused to the divergicin A signal peptide is efficiently exported and correctly matured by both Gram-positive and Gram-negative bacteria. In addition, the ability of the heterologous DTS to export class II bacteriocins has been demonstrated (Marugg et al., 1992; Fremaux et al., 1995; Allison et al., 1995a, b; van Belkum \& Stiles, 1995; van Belkum et al., 1997). It appears that the level of bacteriocin production was greatly affected and was dependent on the level of homologies existing between the leader peptides of the bacteriocins.

Mesentericin Y105 is a class II anti-Listeria bacteriocin produced by Leuconostoc mesenteroides (Héchard et al., 1992) that may have application in food preservation. Its genetic determinants have been characterized and its export using the DTS has been suggested (Fremaux et al., 1995). Lactacin F is another class II bacteriocin produced by Lactobacillus johnsonii (Muriana \& Klaenhammer, 1987). The heterologous expression of mesentericin $\mathrm{Y} 105$ was investigated in $L b$. johnsonii using the DTS of lactacin F; however, very poor expression of mesentericin Y105 was obtained (Fremaux et al., 1995). Thus, in this study, the efficiency of the GSP for expression of mesentericin Y105 was evaluated using the signal peptide of divergicin A. In addition, by cloning the mesentericin Y105 gene clusters including their putative DTS coding genes, the expression of mesentericin Y105 was tested in various Gram-positive hosts.

\section{METHODS}

Bacterial strains and plasmids. Bacterial strains and plasmids used in this study are listed in Table 1. Escherichia coli DH $5 \alpha$ was propagated on Luria-Bertani agar $(1.5 \%, \mathrm{w} / \mathrm{v})$ or in broth at $37^{\circ} \mathrm{C}$ with shaking as described by Sambrook et al.
(1989). When appropriate, ampicillin, erythromycin, X-Gal and IPTG were used at concentrations of 100,150, 50 and $50 \mu \mathrm{g} \mathrm{ml}^{-1}$, respectively. Erythromycin-resistant transformants of $E$. coli were selected on brain heart infusion (BHI; Difco) agar plates containing erythromycin. Leuconostoc strains were grown in/on MRS (Difco) broth or agar $(1.5 \%$, $\mathrm{w} / \mathrm{v}$ ) at $30^{\circ} \mathrm{C}$. Lactococcus strains were propagated in M17 (Difco) containing glucose $(0.5 \%, \mathrm{v} / \mathrm{v})$ broth or agar $(1.5 \%$, $\mathrm{w} / \mathrm{v})$. LAB transformants were selected with $5 \mu \mathrm{g}$ erythromycin $\mathrm{ml}^{-1}$. Listeria ivanovii BUG 497 was grown at $37^{\circ} \mathrm{C}$ in BHI media.

Bacteriocin sensitivity assays. Bacteriocin activity was assayed by spotting $5 \mu$ l cell-free heat-treated supernatant onto MRS agar $(1.2 \%, \mathrm{w} / \mathrm{v})$ plates and overlaying with $5 \mathrm{ml} \mathrm{BHI}$ agar $(0.6 \%, \mathrm{w} / \mathrm{v})$ containing a $1 \%(\mathrm{v} / \mathrm{v})$ inoculum of an overnight culture of List. ivanovii BUG 497. Plates were incubated for $18 \mathrm{~h}$ before analysis.

SDSPAGE analysis. Protein extracts obtained after ammonium sulfate precipitation were concentrated 70 times and diluted $1: 1(\mathrm{v} / \mathrm{v})$ in sample buffer $(2 \times)$ containing $5 \%$ SDS, $12 \%$ glycerol, $2 \% \beta$-mercaptoethanol, $10 \%$ Coomassie brilliant blue $\mathrm{R} 250$ and $50 \mathrm{mM}$ Tris/ $\mathrm{HCl}(\mathrm{pH} \mathrm{6.8)}$. The samples were heated for $10 \mathrm{~min}$ at $100{ }^{\circ} \mathrm{C}$ and loaded on a $16 \%(\mathrm{v} / \mathrm{v})$ polyacrylamide gel in $0.1 \mathrm{M}$ Tris/Tricine ( $\mathrm{pH} \mathrm{8.8)} \mathrm{buffer}$ (Schägger \& von Jagow, 1987), which allowed suitable resolution of low-molecular-mass peptides. Electrophoresis was carried out at constant voltage $(100 \mathrm{~V})$ for $2 \mathrm{~h}$. Gels were fixed in $50 \%(\mathrm{v} / \mathrm{v})$ methanol and $10 \%(\mathrm{v} / \mathrm{v})$ aqueous acetic acid for $20 \mathrm{~min}$. Duplicate gels were performed. One of them was stained with Coomassie brilliant blue R250 to evaluate the molecular mass of the molecules contained in the sample. The second gel was washed with sterile water for $2 \mathrm{~h}$, placed on a BHI agar plate and overlaid with $5 \mathrm{ml} \mathrm{BHI}$ agar $(0.6 \%$, $\mathrm{w} / \mathrm{v})$ inoculated with $1 \%(\mathrm{v} / \mathrm{v})$ of a stationary phase culture of List. ivanovii BUG 497. The inhibition zones were examined after $18 \mathrm{~h}$ incubation at $37^{\circ} \mathrm{C}$.

Molecular cloning and transformation. Plasmids from E. coli and LAB were extracted and purified as previously described by Sambrook et al. (1989) and Muriana \& Klaenhammer (1987), respectively. Plasmid DNA was digested with restriction enzymes (Gibco-BRL) according to the supplier's recommendations. Both analytical and preparative agarose gel electrophoresis in Tris/borate/EDTA (pH 8.3) were performed according to the methods described by Sambrook et al. (1989). DNA restriction fragments were purified from agarose gels using the Prep-a-Gene kit (Bio-Rad). Recombinant DNA was obtained using T4 DNA ligase (Gibco-BRL) following the manufacturer's recommendations. E. coli competent cells were prepared and transformed according to Hanahan (1983).

Leuconostoc cells were transformed by electroporation in $0.2 \mathrm{~cm}$ cuvettes using a Gene Pulser apparatus (Bio-Rad; settings $25 \mu \mathrm{F}, 2.5 \mathrm{kV}, 200 \Omega$ ). Electrocompetent cells were prepared according to the method of Raya et al. (1992). Electrocompetent Lactococcus lactis cells were prepared and transformed according to the method of Holo \& Nes (1989).

DNA sequences were determined with an automated DNA sequencer (ALF; Pharmacia) using the Auto-read sequencing kit (Pharmacia) and appropriate primers. Sequence analyses were performed with the GCG sequence analysis software.

Oligonucleotides and PCRs. Primers FBp1 (5'-AAGAAGCTTCTGCTAAGTATTATGGGAATGGTG) and FBp2 (5'CTCAAGCTTACTGATCGAAAACGCTG) were used for the PCR amplification of the fragment devoted to the secretion 
Table 1. Bacterial strains and plasmids

\begin{tabular}{|c|c|c|}
\hline Strain/plasmid & Relevant characteristics & Source/reference \\
\hline \multicolumn{3}{|l|}{ Strains } \\
\hline \multicolumn{3}{|l|}{ Escherichia coli } \\
\hline $\mathrm{DH} 5 \alpha$ & $\begin{array}{l}\text { recA endA1 gyrA96 thi-1 hsdR17 supE44 } \Delta l a c \mathrm{U} 169(\phi 80 \\
\mathrm{d} l a c \mathrm{Z} \Delta \mathrm{M} 15) \text { deoR } \mathrm{F}^{-} \lambda^{-}\end{array}$ & Gibco-BRL \\
\hline \multicolumn{3}{|c|}{$\begin{array}{l}\text { Leuconostoc mesenteroides } \\
\text { subsp. mesenteroides }\end{array}$} \\
\hline Y105 & Wild-type strain & Héchard et al. (1992) \\
\hline FR52 & Wild-type strain & Mathieu et al. (1993) \\
\hline \multicolumn{3}{|c|}{$\begin{array}{l}\text { Leuconostoc mesenteroides } \\
\text { subsp. dextranicum }\end{array}$} \\
\hline DSM 20484 & Wild-type strain & DSM \\
\hline \multicolumn{3}{|c|}{ Leuconostoc cremoris } \\
\hline $\mathrm{LC}$ & Wild-type industrial strain & Texel \\
\hline \multicolumn{3}{|c|}{ Lactococcus lactis } \\
\hline IL1403 & Laboratory strain & Chopin et al. (1984) \\
\hline RD230 & Wild-type industrial strain & Texel \\
\hline \multicolumn{3}{|l|}{ Listeria ivanovii } \\
\hline BUG 497 & Laboratory strain & Institut Pasteur \\
\hline \multicolumn{3}{|l|}{ Plasmids } \\
\hline pBSSKII + & pBluescript II SK(+) cloning vector, $\mathrm{Ap}^{\mathrm{r}}$, lacZ, $2.96 \mathrm{~kb}$ & Stratagene \\
\hline pGKV210 & E. coli-LAB shuttle vector, $\mathrm{Em}^{\mathrm{r}}, 4.4 \mathrm{~kb}$ & van der Vossen et al. (1985) \\
\hline pGKV259 & E. coli-LAB shuttle expression vector, $\mathrm{Em}^{r} \mathrm{Cm}^{\mathrm{r}}, 5 \mathrm{~kb}$ & van der Vossen et al. (1987) \\
\hline pTRKH2 & Lactococcal cloning vector $l a c Z, \mathrm{Ap}^{\mathrm{r}}, 6.9 \mathrm{~kb}$ & O’Sullivan \& Klaenhammer (1993) \\
\hline pHY30 & mesYI mesCDE, $35 \mathrm{~kb}$ plasmid from $L n$. mesenteroides & Fremaux et al. (1995) \\
\hline pCD3.4 & $\begin{array}{l}\text { dunA dvnl, } 3.4 \mathrm{~kb} \text { plasmid from Carnobacterium } \\
\text { divergens }\end{array}$ & Worobo et al. (1995) \\
\hline pRW5.6 & pGKV259::514 bp EcoRV-AccI fragment from pCD3.4 & Worobo et al. (1995) \\
\hline pFBYC01 & $\begin{array}{l}\text { pBSSKII + : : } 121 \text { bp EcoRV-HindIII fragment from } \\
\text { pCD3.4 }\end{array}$ & This study \\
\hline pFBYC02 & pFBYC01::485 bp dvnA::mes $Y$, mesI PCR product & This study \\
\hline pFBYC03 & pFBYC01::557 bp dvnA::pre-mesY, mesI PCR product & This study \\
\hline pFBYC06 & pRW5.6AHindIII & This study \\
\hline pFBYC07 & pFBYC06::485 bp dvnA::mes $Y$, mesI PCR product & This study \\
\hline pFBYC04 & pTRKH2::7 kb PstI-DraII fragment from pHY30 & This study \\
\hline pCFYC5 & pGKV210:: $1.7 \mathrm{~kb}$ PstI-NsiI fragment from pHY30 & Fremaux et al. (1995) \\
\hline
\end{tabular}

of mesentericin Y105 (Fig. 1a). They were designed in order to generate HindIII restriction sites at both ends of the PCR product. The five nucleotides downstream of the HindIII site of FBp1 encode the C-terminus of the divergicin A signal peptide, and the remaining 19 residues are identical to the $5^{\prime}$ end of the sequence encoding the mature mesentericin Y105. In addition to the HindIII site, FBp2 is complementary to the sequence encoding the C-terminus of the mesentericin Y105 immunity protein. For the PCR amplification of the DNA fragment devoted to the secretion of the pre-mesentericin Y105 (Fig. 1b), primers FBp3 (5'-AAGAAGCTTCTGCTATGACGAATATGAAGTCTGTG) and FBp2 were used. The primer FBp3 was designed similarly to $\mathrm{FBp} 1$; its $3^{\prime}$ end is identical to the $5^{\prime}$ end of the mesentericin Y105 structural gene. PCR reactions on pHY30 (Fremaux et al., 1995) were performed with the Taq DNA polymerase from Perkin ElmerCetus according to the supplier's recommendations using the Gene Ataq thermocycler (Pharmacia) under the following conditions: 35 cycles of denaturation at $94^{\circ} \mathrm{C}$ for $10 \mathrm{~s}$, annealing at $48^{\circ} \mathrm{C}$ for $10 \mathrm{~s}$ and elongation at $72^{\circ} \mathrm{C}$ for $20 \mathrm{~s}$.
Production and purification of mesentericin Y105. Leuconostoc strains were propagated $(1 \%, \mathrm{v} / \mathrm{v}$, inoculum $)$ in $100 \mathrm{ml}$ MRS broth for $24 \mathrm{~h}$ at $30^{\circ} \mathrm{C}$ (final $\mathrm{OD}_{600} \approx 4$ ) and cells were harvested by centrifugation at $6000 \mathrm{~g}$ for $15 \mathrm{~min}$ at $4^{\circ} \mathrm{C}$. After heating of the cell-free supernatant at $70^{\circ} \mathrm{C}$ for $30 \mathrm{~min}$, the bacteriocin was precipitated with ammonium sulfate $\left(360 \mathrm{~g} \mathrm{l}^{-1}\right)$ with constant stirring at $4^{\circ} \mathrm{C}$ for $18 \mathrm{~h}$ and harvested by centrifugation $\left(13000 \mathrm{~g}, 45 \mathrm{~min}, 4^{\circ} \mathrm{C}\right)$. The pellet was resuspended in $10 \mathrm{ml}$ water. The solution was loaded on a reverse-phase cartridge (C18 Sep-pak plus; Waters) and was eluted in steps with $5 \mathrm{ml} 0,10,20,30,40,60$ and finally $80 \%$ $(\mathrm{v} / \mathrm{v})$ acetonitrile solutions in $20 \mathrm{mM}$ ammonium acetate. Fractions were assayed for bacteriocin activity by the spot-onlawn test. Reverse-phase HPLC was conducted on a Spectra Physics Analytical apparatus. Lyophilized active fractions were solubilized in $1 \mathrm{ml}$ water before injection on a C8 column Kromasil ( 250 by $4.6 \mathrm{~mm}, 5 \mu \mathrm{m}$ particle size, $10 \mathrm{~nm}$ pore size, flow rate $0.8 \mathrm{ml} \mathrm{min}^{-1}$ ). Separation was carried out using a water/acetonitrile/trifluoroacetic acid, $0.1 \%(\mathrm{v} / \mathrm{v})$, solvent system with an elution gradient of $16-64 \%$ acetonitrile over 
(a)

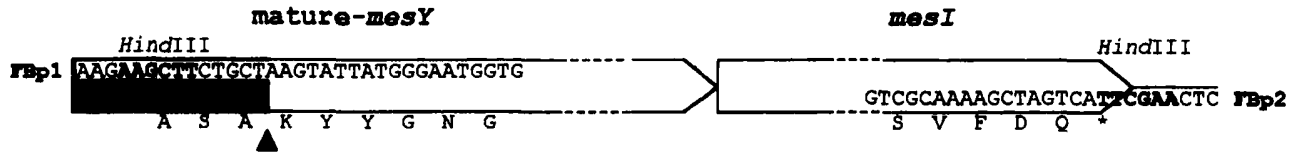

(b)

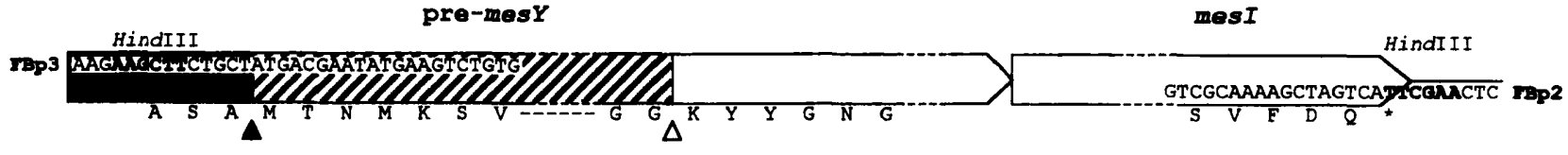

Fig. 1. Schematic representation of the PCR fragments synthesized from pHY 30 for the construction of the plasmids devoted to the secretion of (a) mesentericin Y105 and (b) the mesentericin Y105 precursor. Boxes represent genes that have been amplified by PCR with the primer sequences given within. The black and the dashed parts of the boxes correspond to sequences encoding the C-terminus of the divergicin A signal peptide and the mesentericin Y105 leader peptide, respectively, whereas open boxes represent genes encoding the mesentericin Y105 immunity protein (mesl) and the mature form of mesentericin Y105 (mesY). Relevant gene translation is given below the boxes; $\mathbf{\Delta}$, divergicin A signal peptide cleavage site; $\triangle$, mesentericin Y105 leader peptide cleavage site. The HindIII restriction sites introduced within the primer sequences are indicated.

$37 \mathrm{~min}$. Elutions were monitored by measuring the $A_{220}$ and $A_{280}$. All fractions corresponding to the detected peaks were assayed for activity against the indicator strains.

Protein analysis. The mass spectra of the purified mesentericin Y105 samples were obtained from positive ionspray analysis on a Perkin-Elmer Sciex API 165 mass spectrometer equipped with an ionspray source. Lyophilized active samples purified by HPLC were dissolved in a $0.25 \mathrm{ml}$ solution of acetonitrile/ water $(1: 1)$ containing $0.1 \%$ formic acid and infusion injected

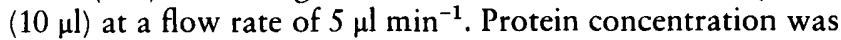
determined by using the bicinchoninic acid protein assay kit (Sigma) according to the manufacturer's instructions.

\section{RESULTS}

\section{Heterologous production of mesentericin $\mathrm{Y} 105$ and its precursor using the GSP in E. coli}

Preliminary experiments performed in E. coli strains attempted to investigate the secretion of mesentericin Y105 by the GSP. A secretion vector, pFBYC01, was constructed on the basis of the utilization of the divergicin A signal peptide placed under the control of the inducible lac promoter, as described in Fig. 2. To generate pFBYC01, the EcoRV-HindIII fragment from pCD3.4 (Worobo et al., 1995) containing a ribosomebinding site and part of the divergicin A signal peptide gene was cloned into pBSSKII + restricted with SmaI and HindIII enzymes.

To obtain a DNA fragment encoding a mature form of mesentericin Y105 and its immunity protein, a region of pHY30 (Fremaux et al., 1995) was amplified by PCR using the primers FBp1 and FBp2 (Fig. 1a). The Ala-SerAla cleavage site of the divergicin signal peptide, which is truncated in the EcoRV-HindIII fragment, was regenerated by the residues incorporated into the sequence of the PCR primer FBp1. The PCR fragment was digested with HindIII and cloned into pFBYC01 at the unique HindIII site to form the mesentericin Y105 secretion plasmid pFBYC02 (Fig. 2). Sequence analysis confirmed the accuracy of the gene fusion and ensured that the correct reading frame was maintained between the sequence encoding the divergicin A signal peptide and the mesentericin Y105 structural gene, devoid of its natural leader peptide. In this construction, the transcription of the fused gene is under the control of the inducible lac promoter on pBSSKII +. Sequence analysis also revealed the presence of a small ORF, beginning from the lac $Z$ start codon, which overlaps the fused gene and its translation initiation signals (the ribosomebinding site and the start codon of $\operatorname{dvnA}$ ). To prevent any inefficient recognition of these signals, the SacI restriction site located within this small ORF was opened and then blunt-ended before ligation, generating a shift in the reading frame and stop codons. Secretion of mesentericin Y105 was tested by introducing pFBYC02 into $E$. coli $\mathrm{DH} 5 \alpha$ cells. Upon induction with $1 \mathrm{mM}$ IPTG at an OD $_{600}$ of $1(1 \mathrm{~cm}$ cuvette, Hitachi U-1100 spectrophotometer), the expression of an antagonistic activity within the culture supernatant was detected by the spot-on-lawn test against a sensitive indicator strain. The activity was then analysed by an SDS-PAGE overlay assay (Fig. 3). The apparent molecular mass of the active peptide secreted by E. coli (Fig. 3, lane 1) was in accordance with that of the natural bacteriocin used as a control (Fig. 3, lane 4). Full induction of the antagonist in E. coli DH $5 \alpha$ caused a decline of the culture turbidity, suggesting the lysis of induced cells (data not shown).

The biochemical and structural characterization of the mesentericin Y105 precursor will first require its purification. However, it is likely to be transitorily present in the natural mesentericin Y105 producer strain and therefore difficult to purify. Consequently, we constructed the plasmid pFBYC03 to secrete the mesentericin Y105 precursor (Fig. 2). For pFBYC03 construction, the cloning strategy was identical to that described for pFBYC02, except that the PCR fragment 

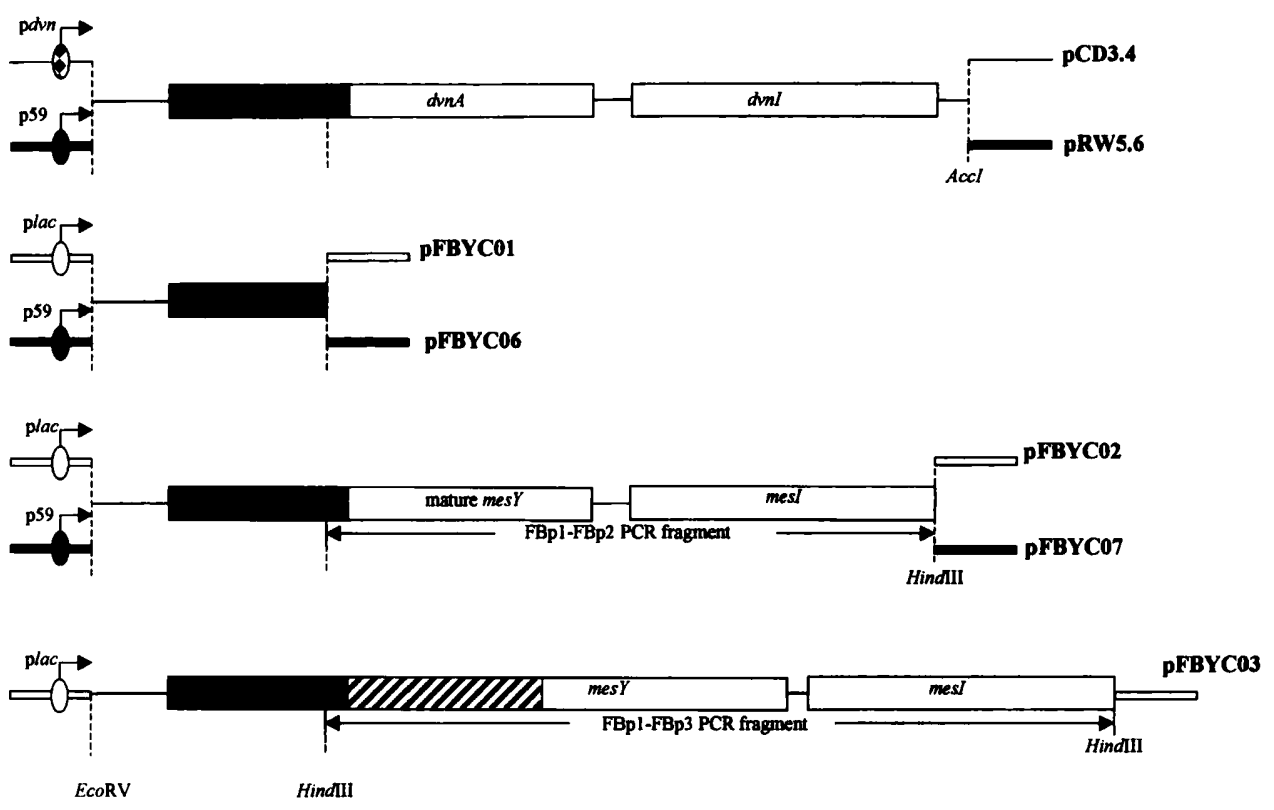

Fig. 2. Schematic representation of the relevant features of the plasmids (names are given on the right of the schemes) constructed for the secretion of mesentericin $Y 105$ and of the mesentericin $Y 105$ precursor. The boxes represent the natural or the constructed bacteriocin genes (dvnA for divergicin $A$ and mes $Y$ for mesentericin $Y 105$ ) and their corresponding immunity genes ( $d v n l$ and mes/). The black and the dashed parts of the boxes indicate the sequences encoding the divergicin A signal peptide and the mesentericin Y105 leader peptide, respectively. The promoters driving the transcription of the genes are shown on the left of the figure: pdvn, the natural promoter of the divergicin A operon; p59, a lactococcal constitutive promoter; and plac, the inducible promoter of the $E$. coli lactose operon. Relevant restriction sites are indicated.

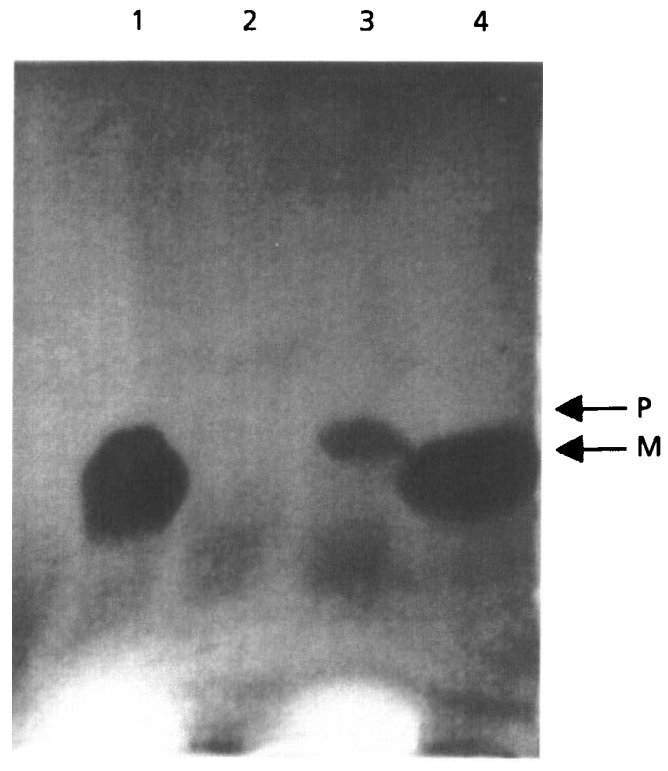

Fig. 3. Detection of antagonistic activity against List. ivanovii BUG 497 in spent culture supernatant following Tricine-SDSPAGE. Lanes: 1 , concentrated supernatant $(70 \times)$ of $E$. coli DH5 $\alpha$ (pFBYC02); 2 , concentrated supernatant $(70 \times)$ of $E$. coli DH5 $\alpha$ (pBSSKII +$) ; 3$, concentrated supernatant $(70 \times)$ of $E$. coli DH5 $\alpha$ (pFBYC03); 4, supernatant of $L n$. mesenteroides Y105. M, Inhibition zone associated with the bactericidal activity of mesentericin $\mathrm{Y} 105$; $\mathrm{P}$, inhibition zone associated with the putative antagonism of the mesentericin $\mathrm{Y} 105$ precursor. (using primers $\mathrm{FBp} 2$ and $\mathrm{FBp} 3$ ) cloned into the HindIII site of pFBYC01 contains the whole structural gene of mesentericin Y105, including the part encoding the Nterminal extension of mesentericin Y105 (Fig. 1b). After transformation of pFBYC03 into E. coli $\mathrm{DH} 5 \alpha$ and induction of the cloned gene, the presence of an active peptide against Listeria was determined by an SDSPAGE overlay assay (Fig. 3). This peptide has an apparent molecular mass higher than that of the natural mesentericin Y105, and thus is likely to be the premesentericin Y105. From the SDS-PAGE overlay assay, it appeared to be less active compared to mesentericin Y105, as confirmed by the absence of cell lysis upon induction by IPTG (not shown).

\section{Heterologous production of mesentericin Y105 using the GSP in Leuconostoc}

A secretion vector that replicates in $\mathrm{LAB}$ was developed using plasmid pRW5.6 constructed by Worobo et al. (1995). In this plasmid, the divergicin A operon is under the control of the constitutive lactococcal promoter $\mathrm{p} 59$ (Fig. 2). Plasmid pRW5.6 was digested with HindIII, deleting part of the divergicin A structural gene and its immunity gene, then self-ligated to construct pFBYC06 (Fig. 2). Similarly to pFBYC02, a PCR-generated DNA (using primers $\mathrm{FBp} 1$ and $\mathrm{FBp} 2$ ) encoding a mature form of mesentericin Y105 and its immunity protein with 
HindIII linking ends, was inserted into the HindIII site of pFBYC06, yielding the pFBYC07 plasmid (Fig. 2). Although the pFBYC07 replicon was functional in $E$. coli strains, no transformant was obtained with pFBYC07 in this organism probably because of the toxicity of mesentericin Y105. Alternatively, the ligation mixture of pFBYC07 was electroporated into $L n$. mesenteroides DSM 20484. This strain, deprived of antiListeria activity, gave a high number of transformants by electroporation, and thus allowed direct transformation with ligation mixtures. Erythromycin-resistant clones of Ln. mesenteroides DSM 20484 obtained after electroporation were screened for antagonistic activity against Listeria by spot-on-lawn tests. They exhibited activity against the indicator strain (data not shown) and were found to contain pFBYC07. Similar results were obtained with pFBYC07 introduced into the industrial strain Leuconostoc cremoris LC.

\section{Heterologous production of mesentericin Y105 using the DTS in Leuconostoc}

Plasmid pCFYC5 contains the mesentericin Y105 structural gene (mes $\mathrm{Y}$ ) and its immunity gene (mesI) (Fremaux et al., 1995). When introduced into $L n$. mesenteroides DSM 20484, the resulting strain failed to produce any bactericidal activity against Listeria or $\mathrm{LAB}$, suggesting that some essential functions are missing within the cloned fragment for the production of the bacteriocin. Previous analyses of the mesentericin Y105 genetic locus (Fremaux et al., 1995) revealed the presence of an operon containing three putative genes (mes $C$, mes $D$ and mesE) that may be involved in the specific transport of mesentericin Y105. Indeed, mesD and mesE encode the two components of a putative ATP-binding cassette transport system.

A $7 \mathrm{~kb}$ PstI-Drall restriction fragment containing mesYICDE was introduced into pTRKH2, a high-copynumber $E$. coli-LAB shuttle vector (O'Sullivan \& Klaenhammer, 1993). The resulting plasmid, pFBYC04 (Table 1), was able to direct the production in $L n$. mesenteroides DSM 20484 of a bactericidal compound active against Listeria. Similarly, the industrial $L n$. cremoris LC strain produced an antagonistic activity against Listeria when electroporated with pFBYC04. This demonstrates that mesC, mesD and/or mesE are required for the expression of mesentericin Y105. It has been shown in a highly homologous bacteriocin, leucocin A (van Belkum \& Stiles, 1995), by gene inactivation that similar dedicated transport genes are required for export.

\section{Analysis of mesentericin Y105 expressed in Ln. mesenteroides}

The antagonistic compound, produced by Ln. mesenteroides DSM 20484 transformed with pFBYC04 and pFBYC07, was purified from cell-free culture supernatants by a three-step protocol involving ammonium sulfate precipitation, C18 solid-phase extraction and

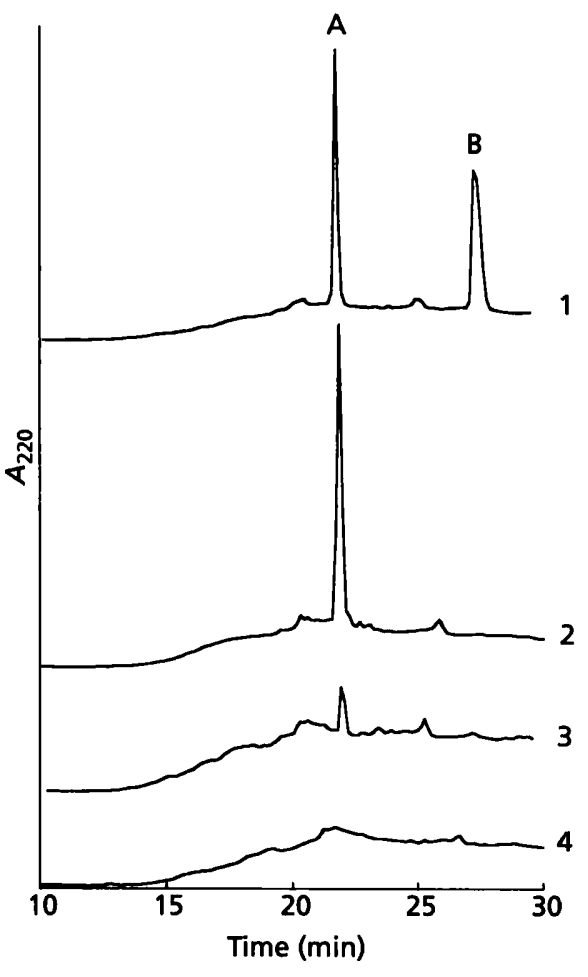

Fig. 4. Reverse-phase HPLC elution profiles (C8 Kromasil AIT) of active fractions obtained after cartridge chromatography of concentrated spent culture supernatants from: $L n$. mesenteroides Y105 (lane 1); Ln. mesenteroides DSM 20484(pFBYC04) (lane 2); Ln. mesenteroides DSM 20484(pFBYC07) (lane 3); control, homologous fraction from Ln. mesenteroides DSM 20484 (lane 4).

reverse-phase HPLC. Almost all of the antagonistic activity was found in the ammonium sulfate pellet. After resuspending this pellet in water, proteins were fractionated on C18 cartridges using an increasing acetonitrile step gradient. The active fraction eluted at $40 \%$ acetonitrile was further purified by reverse-phase HPLC. The elution profiles showed a single protein peak at a retention time of 22 min (peak A; Fig. 4). The biological activity of the HPLC fractions corresponding to the peaks was assayed against the indicator strain, revealing an antagonistic activity. The purified protein was subjected to MS analysis using an ionspray ionization source instrument. As shown in Fig. 5(a), the final estimated mass was $3868 \cdot 27 \pm 0 \cdot 25 \mathrm{Da}$ for the purified peptide from $L n$. mesenteroides DSM 20484 containing either pFBYC04 or pFBYC07. This value corresponds to the molecular mass of mesentericin Y105 purified from the supernatant of the natural producer strain $L n$. mesenteroides Y105 (lane 1, peak A; Fig. 4), and is in agreement with the theoretical molecular mass for an oxidized form of mesentericin Y105 calculated from its amino acid sequence (Fremaux et al., 1995). The amount of mesentericin Y105 purified from a culture of each of the transformants and of the natural producer was estimated. A similar amount of mesentericin Y105 was obtained from a $100 \mathrm{ml}$ culture of $\mathrm{Ln}$. mesenteroides 


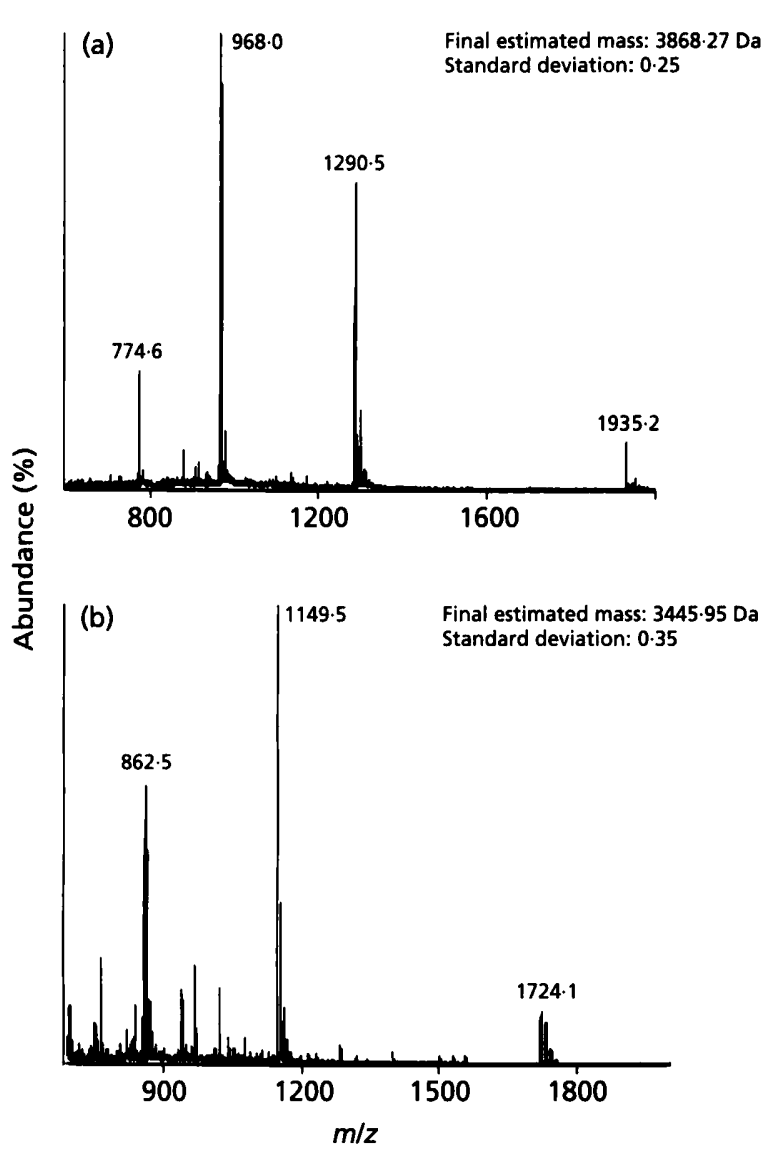

Fig. 5. lonspray mass spectra of the purified fractions from $L$. mesenteroides $\mathrm{Y} 105$ of (a) peak A and (b) peak B obtained after reverse-phase HPLC (see Fig. 4, lane 1).

DSM 20484(pFBYC04) and Ln. mesenteroides Y105 (142 and $129 \mu \mathrm{g}$, respectively), whereas $34 \mu \mathrm{g}$ mesentericin Y105 was obtained from Ln. mesenteroides DSM 20484(pFBYC07), under identical culture conditions and using the same purification procedure. In addition to peak A corresponding to mesentericin Y105, a second protein peak (lane 1, peak B; Fig. 4) was revealed on a HPLC chromatogram from a culture of the natural mesentericin Y105 producer. Peak B, with a $27.7 \mathrm{~min}$ retention time, showed an antagonistic activity against Leuconostoc strains (data not shown) but not Listeria, suggesting the production of a second bacteriocin. Indeed, it is not likely to correspond to a degradation product from mesentericin Y105, since it was not detected in Ln. mesenteroides DSM 20484(pFBYC04) culture supernatant. Mass spectrum analysis of peak B gave a molecular mass of $3445.95 \pm 0.35 \mathrm{Da}$ (Fig. $5 \mathrm{~b}$ ). With respect to the molecular mass, this compound resembles mesenterocin 52B, previously described by Revol-Junelles et al. (1996), a class II bacteriocin known for its activity against Leuconostoc strains but not Listeria. Our results demonstrate the production of a second bacteriocin by Ln. mesenteroides Y105 that was not previously detected because mesentericin Y105 masked its activity in spot-on-lawn tests.

\section{Heterologous expression of mesentericin Y105 in LC. lactis}

To further study the heterologous expression of mesentericin Y105, plasmids pFBYC04 and pFBYC07 were also introduced into Lc. lactis strains IL1403 and RD230. The ability of the transformants to produce mesentericin Y105 was examined. None of the supernatants of $L c$. lactis/pFBYC04 or Lc. lactis/pFBYC07 transformants revealed any detectable antagonistic activity. These data cannot be correlated to a transcriptional deficiency, since Northern blot hybridization revealed the presence of the expected transcript (data not shown). To test if, in Lactococcus, mesentericin $\mathrm{Y} 105$ is expressed in an inactive form or alternatively is not present at all in the extracellular medium, we looked for its presence in the supernatant as described before. The HPLC chromatogram did not show any peak at a retention time of $22 \mathrm{~min}$. This seems to confirm the inability to produce mesentericin Y105 from pFBYC07 or pFBYC04 in Lactococcus.

\section{DISCUSSION}

Large quantities of a bacteriocin are required for structural analysis. In attempts to obtain a sufficient amount of mesentericin Y105 for elucidating its spatial conformation, we investigated its heterologous expression in various bacterial species using two export systems: (i) the GSP and (ii) the putative mesentericin Y105 DTS.

First, we took advantage of the divergicin A signal peptide (Worobo et al., 1995) for the construction of two plasmids (pFBYC03 and pFBYC02) capable of secreting the mesentericin Y105 precursor and the mature mesentericin Y105, respectively. In these plasmids, the structural gene of mesentericin Y105 or the part of the gene encoding the mature peptide is fused to the signal peptide of the divergicin A encoding region. This synthetic gene was placed under the control of the $\beta$-galactosidase inducible promoter. Cloned in E. coli DH $5 \alpha$, the two plasmids allowed the production of both peptides. Interestingly, the bacteriocin precursor (that possessed a $24 \mathrm{~N}$-terminal amino acid extension) exhibited a weak antagonistic activity against Listeria. This is in agreement with the observation by Quadri et al. (1997) for the carnobacteriocin B2 precursor. Previous work demonstrated the ability of $E$. coli to produce heterologous bacteriocins originated from LAB. Pediocin PA-1 was produced via its own DTS (Marugg et al., 1992) and divergicin A was exported using the leucocin $\mathrm{A}$ or colicin $\mathrm{V}$ export machinery (van Belkum et al., 1997). On the contrary, divergicin A failed to be produced by E. coli using the lactococcin A DTS (van Belkum et al., 1997). In our case, very poor antagonistic activity (about 100 times less than the natural producer) was detected in the supernatant of E. coli DH5 $\alpha$ (pFBYC02) cultures. Nevertheless, the divergicin A signal peptide was shown to efficiently direct the production of alkaline phosphatase to the culture supernatant in E. coli (Worobo et al., 1995). However, 
these authors reported that one-third of the secreted alkaline phosphatase was located within the periplasm. In addition, although colicin $\mathrm{V}$ is efficiently secreted across the cytoplasmic membrane via the GSP, secretion through the outer membrane is not achieved and the molecule is trapped within the periplasm (Zhang et al., 1995). Despite previous analyses demonstrating that mesentericin Y105 was inactive on whole cells of $E$. coli, upon IPTG induction, cell lysis was observed in E. coli $\mathrm{DH} 5 \alpha(\mathrm{pFBYC02})$ cultures. This result, together with the low level of production, suggested that at least a part of mesentericin Y105 is trapped within the periplasm and that the toxicity of mesentericin Y105 may lead to cell lysis. Interestingly, a lytic activity of mesentericin Y105 on mitochondria (Maftah et al., 1993) and erythrocytes (A. Maftah, personal communication) was previously described. These three lots of data suggest that mesentericin Y105 may act without the intermediate of a specific receptor when the cytoplasmic membrane is directly accessible. Thus, the cell wall is likely to give its specificity to the bacteriocin. The immunity protein may ensure the cytoplasmic membrane integrity and may not be expressed enough in the E. coli $\mathrm{DH} 5 \alpha(\mathrm{pFBYC02})$ strain. Indeed, we were unable to construct an $E$. coli strain expressing mesentericin $\mathrm{Y} 105$ in which the immunity gene was disrupted, suggesting that pFBYC02 encodes a functional immunity protein in E. coli.

The toxicity of mesentericin Y105 produced by a Gramnegative host led us to investigate the secretion of the bacteriocin in Lactococcus and Leuconostoc. Heterologous expression in Lc. lactis of bacteriocins fused to the divergicin A signal peptide has been investigated previously. Divergicin A and carnobacteriocin B2 were found to be secreted by Lc. lactis (Worobo et al., 1995; McCormick et al., 1996), proving the efficiency of the GSP for the expression of bacteriocins in Gram-positive

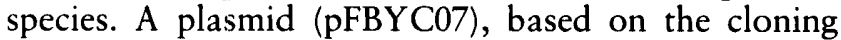
vector pGKV259, was constructed in which the gene encoding the secreted mesentericin Y105 is under the control of the constitutive lactococcal promoter $\mathrm{p} 59$. Three lactococcal strains (laboratory strains IL1403 and MG1363 and one industrial strain RD230) transformed with pFBYC07 failed to produce any detectable amount of bacteriocin. Plasmid pFBYC07 was then isolated from one of the lactococcal transformants and used to transform Leuconostoc strains. In contrast to Lc. lactis strains, all the Leuconostoc transformants were found to produce small amounts of mesentericin Y105 in the culture supernatant. Low level secretion of mesentericin Y105 is consistent with the weak activity detected for the secreted divergicin A and carnobacteriocin B2 in heterologous hosts (Worobo et al., 1995; McCormick et al., 1996).

Leucocin A is an anti-Listeria peptide closely related to mesentericin Y105 (Hastings et al., 1991). These two peptides only differ by two residues, alanine 22 (mesentericin Y105) versus phenylalanine (leucocin A) and isoleucine 26 versus valine. These differences are conservative changes, and thus one can expect leucocin A to behave similarly to mesentericin Y105. Leucocin A has been produced previously in Lc. lactis, using its own DTS (van Belkum et al., 1997). To understand the problems encountered for the secretion in Lc. lactis, similar constructs were made with the mesentericin Y105 genetic determinants. Firstly, plasmid pCFYC5, which contains the mesentericin Y105 structural gene and its corresponding immunity gene, was constructed and introduced in Ln. mesenteroides DSM 20484, a strain devoid of antagonistic activity. Transformants failed to produce any detectable bacteriocin activity. Secondly, another construct, pFBYC04, which contains the entire mesentericin Y105 gene cluster described by Fremaux et al. (1995), was introduced in this strain. The resulting clones displayed bactericidal activity against Listeria, demonstrating the presence within the cloned fragment of the genes encoding the DTS for mesentericin Y105, as proposed previously by Fremaux et al. (1995). However, similarly to pFBYC07, plasmid pFBYC04 cloned in Lc. lactis failed to produce mesentericin Y105. Northern blot analysis proved that the mesentericin Y105 gene cluster in pFBYC04 and the $\operatorname{dvnA::mesY}$ gene fusion in pFBYC07 were well transcribed in Lactococcus (data not shown). In addition, bacteriocin genes originating from $\mathrm{LAB}$ are usually efficiently translated in Lactococcus and this species was shown to be capable of exporting and processing a few bacteriocins from other LAB species (Worobo et al., 1995; van Belkum \& Stiles, 1995; van Belkum et al., 1997; Horn et al., 1998). Thus, we suspect that difficulties encountered in producing mesentericin $\mathrm{Y} 105$, but not leucocin A, in Lactococcus may be associated with either peptide degradation or trapping specified by the bacteriocin sequence itself. Indeed, lactococcal strains are known to produce many peptidases (Kunji et al., 1996) and the binding properties of bacteriocins have been previously reported (Coventry et al., 1996). It is, however, interesting to note that failure to produce a bacteriocin using its own DTS in a heterologous host has already been described (van Belkum et al., 1997).

The level of mesentericin Y105 expression by recombinant and wild-type Leuconostoc strains was evaluated through a new three-step purification method. This mesentericin Y105 purification strategy appeared to be highly reproducible and more efficient than previously described methods (Héchard et al., 1992; Revol-Junelles et al., 1996). Comparison of the yield of purified bacteriocin showed that mesentericin Y105 is produced about three times more when exported by its own DTS, i.e. $>1 \mathrm{mg} \mathrm{l}^{-1}$ for cultures of Ln. mesenteroides Y105 and Ln. mesenteroides DSM 20484(pFBYC04), than by the GSP, i.e. $\sim 300 \mu \mathrm{g}^{-1}$ for a culture of Ln. mesenteroides DSM 20484(pFBYC07). However, this may be not only related to the efficiency of the export system itself (DTS versus GSP), but also to gene copy numbers (pTRKH2 versus pGKV259) and/or promoter efficiencies (mesentericin Y105 promoter versus $\mathrm{p} 59$ promoter).

Very few industrial LAB are known to produce bacteriocins. To take advantage of these GRAS (Generally Recognized As Safe) antagonistic peptides in the control 
of spoilage and pathogenic bacteria, various strategies have been proposed previously to produce bacteriocins in heterologous hosts, especially in industrial strains. The secretion pathway appeared to be a 'premium' choice because of its ubiquity among bacteria. The feasibility of bacteriocin secretion has been shown (Worobo et al., 1995; McCormick et al., 1996). However, we demonstrated that bacteriocin yield was poor and may not fit industrial requirements. Some authors also investigated the possibility of producing multiple bacteriocins using the DTS of other bacteriocins (Allison et al., 1995a, b; Fremaux et al., 1995; van Belkum \& Stiles, 1995). They demonstrated the poor efficiency of such heterologous association, suggesting that DTSs are someway specific for a bacteriocin. Thus, the leader peptide associated with its own DTS fused to a mature peptide seemed to be an attractive alternative. However, at least for mesentericin Y105, the primary sequence of the bacteriocin affects the efficiency of its expression. Therefore, it appears that the best compromise consists in the production of bacteriocins by strains of 'homologous genera' using their own DTS. For example, we were able to express the mesentericin Y105 in an industrial strain, namely $\mathrm{Ln}$. cremoris LC, at a similar level to that of the natural producer. In addition, such approaches are more likely to be in accordance with legal issues concerning the release of genetically modified micro-organisms.

\section{ACKNOWLEDGEMENTS}

This work has been achieved as a part of the program BIOAVENIR (contract no. 780227) supported by RhônePoulenc with the participation of the Ministere de la Recherche et de l'Espace and the Ministère de l'Industrie et du Commerce Extérieur.

\section{REFERENCES}

Allison, G. E., Ahn, C., Stiles, M. E. \& Klaenhammer, T. R. (1995a). Utilisation of the leucocin A export system in Leuconostoc gelidum for production of a Lactobacillus bacteriocin. FEMS Microbiol Lett 131, 87-93.

Allison, G. E., Worobo, R. W., Stiles, M. E. \& Klaenhammer, T. R. (1995b). Heterologous expression of the lactacin F peptides by Carnobacterium piscicola LV17. Appl Environ Microbiol 61, 1371-1377.

Axelsson, L. \& Holck, A. (1995). The genes involved in production of and immunity to sakacin A, a bacteriocin from Lactobacillus sake Lb706. J Bacteriol 177, 2125-2137.

van Belkum, M. J. \& Stiles, M. (1995). Molecular characterization of genes involved in the production of the bacteriocin leucocin A from Leuconostoc gelidum. Appl Environ Microbiol 61, 35733579.

van Belkum, M. J., Worobo, R. W. \& Stiles, M. (1997). Doubleglycine-type leader peptides direct secretion of bacteriocins by $\mathrm{ABC}$ transporters : colicin V secretion in Lactococcus lactis. Mol Microbiol 23, 1293-1301.

Bukhtiyarova, M., Rongguang, Y. \& Ray, B. (1994). Analysis of the pediocin Ach gene cluster from plasmid pSMB74 and its expression in a pediocin-negative Pediococcus acidilactici strain. Appl Environ Microbiol 60, 3405-3408.
Chopin, A., Chopin, M.-C., Miollo-Batt, A. \& Langella, P. (1984). Two plasmid-determined restriction and modification systems in Streptococcus lactis. Plasmid 11, 260-263.

Coventry, M. J., Gordon, J. B., Alexander, M., Hickey, M. W. \& Wan, J. (1996). A food-grade process for isolation and partial purification of bacteriocins of lactic acid bacteria that uses diatomite calcium silicate. Appl Environ Microbiol 62, 1764 1769.

Franke, C. M., Leenhout, K. J., Haandrikman, A. J., Kok, J., Venema, G. \& Venema, K. (1996). Topology of LcnD, a protein implicated in the transport of bacteriocins from Lactococcus lactis. J Bacteriol 176, 1766-1769.

Fremaux, C., Héchard, Y. \& Cenatiempo, Y. (1995). Mesentericin Y105 gene clusters in Leuconostoc mesenteroides Y105. Microbiology 141, 1637-1645.

Hanahan, D. (1983). Studies on transformation of Escherichia coli with plasmid DNA. J Mol Biol 166, 557-580.

Hastings, J. W., Sailer, M., Johnson, K., Roy, K. L., Vederas, J. C. \& Stiles, M. E. (1991). Characterization of leucocin A-UAL 187 and cloning of the bacteriocin gene from Leuconostoc gelidum. J Bacteriol 173, 7491-7500.

Håvarstein, L. S., Diep, D. B. \& Nes, I. F. (1995). A family of bacteriocin $\mathrm{ABC}$ transporters carry out proteolytic processing of their substrates concomitant with export. Mol Microbiol 16, 229-240.

Héchard, Y., Derijard, B., Letellier, F. \& Cenatiempo, Y. (1992). Characterization and purification of mesentericin Y105, an antiListeria bacteriocin from Leuconostoc mesenteroides. J Gen Microbiol 138, 2725-2731.

Higgins, C. F. (1992). ABC transporters: from micro-organisms to man. Annu Rev Cell Biol 8, 67-113.

Holo, H. \& Nes, I. F. (1989). High-frequency transformation, by electroporation, of Lactococcus lactis subsp. cremoris grown with glycine in osmotically stabilized media. Appl Environ Microbiol 55, 3119-3123.

Horn, N., Martínez, M. I., Martínez, J. M., Hernández, P. E., Gasson, M. J., Rodríguez, J. M. \& Dodd, H. M. (1998). Production of pediocin PA-1 by Lactococcus lactis using the lactococcin A secretory apparatus. Appl Environ Microbiol 64, 818-823.

Klaenhammer, T. R. (1993). Genetics of bacteriocins produced by lactic acid bacteria. FEMS Microbiol Rev 12, 39-86.

Kunji, E. R. S., Mierau, I., Hagting, A., Poolman, B. \& Konings, W. N. (1996). The proteolytic systems of lactic acid bacteria. Antonie Leeuwenboek 70, 187-221.

Leer, R. J., van der Vossen, J. M. B. M., van Giezen, M., van Noort, J. M. \& Pouwels, P. H. (1995). Genetic analysis of acidocin B, a novel bacteriocin produced by Lactobacillus acidophilus. Microbiology 141, 1629-1635.

McCormick, J. K., Worobo, R. W. \& Stiles, M. E. (1996). Expression of the antimicrobial peptide carnobacteriocin B2 by a signal peptide-dependent general secretory pathway. Appl Environ Microbiol 62, 4095-4099.

Maftah, A., Renault, D., Vignoles, C., Héchard, Y., Bressollier, P., Ratinaud, M. H., Cenatiempo, Y. \& Julien, R. (1993). Membrane permeabilization of Listeria monocytogenes and mitochondria by the bacteriocin mesentericin Y105. J Bacteriol 175, 3232-323.5.

Marugg, J. D., Gonzales, C. F., Kunka, B. S., Ledeboer, A. M., Pucci, M. J., Toonen, M. Y., Walker, S. A., Zoetmulder, L. C. \& Vandenbergh, P. A. (1992). Cloning, expression, and nucleotide sequence of genes involved in production of pediocin PA-1, a bacteriocin from Pediococcus acidilactici PAC1.0. Appl Environ Microbiol 58, 2360-2367. 
Mathieu, F., Sudirman Suwhandi, I., Rekhif, N., Millière, J. B. \& Lefebvre, G. (1993). Mesenterocin 52, a bacteriocin produced by Leuconostoc mesenteroides subsp. mesenteroides FR52. J Appl Bacteriol 74, 372-379.

Muriana, P. M. \& Klaenhammer, T. R. (1987). Conjugal transfer of plasmid-encoded determinants for bacteriocin production and immunity in Lactobacillus acidophilus 88. Appl Environ Microbiol 53, 553-560.

O'Sullivan, D. \& Klaenhammer, T. R. (1993). High and low-copynumber Lactococcus shuttle cloning vectors with features for clone screening. Gene 137, 227-231.

Quadri, L. E., Kleerebezem, M., Kuipers, O. P., De Vos, W. M., Roy, K. L., Vederas, J. C. \& Stiles, M. E. (1997). Characterization of a locus from Carnobacterium piscicola LV17B involved in bacteriocin production and immunity: evidence for global inducer-mediated transcriptional regulation. J Bacteriol 179, 61636171.

Raya, R. R., Fremaux, C., De Antoni, G. L. \& Klaenhammer, T. R. (1992). Site-specific integration of the temperate bacteriophage $\phi$ adh into the Lactobacillus gasseri chromosome and molecular characterization of the phage $(a t t P)$ and bacterial (attB) attachment site. J Bacteriol 174, 5584-5592.

Revol-Junelles, A. M., Mathis, R., Kier, F., Fleury, Y., Delfour, A. \& Lefebvre, G. (1996). Leuconostoc mesenteroides subsp. mesenteroides FR52 synthesises two distinct bacteriocins. Lett Appl Microbiol 23, 120-124.

Sambrook, J., Fritsch, E. \& Maniatis, T. (1989). Molecular Cloning : a Laboratory Manual, 2nd edn. Cold Spring Harbor, NY: Cold Spring Harbor Laboratory.

Schägger, H. \& von Jagow, G. (1987). Tricine-sodium dodecyl sulfate-polyacrylamide gel electrophoresis for the separation of proteins in the range from 1 to $100 \mathrm{kDa}$. Anal Biochem 166, 368-379.

Stoddard, G. W., Petzel, J. P., van Belkum, M. J., Kok, J. \& McKay, L. L. (1992). Molecular analyses of the lactococcin A gene cluster from Lactococcus lactis subsp. lactis biovar diacetylactis WM4. Appl Environ Microbiol 58, 1952-1961.

van der Vossen, J. M. B. M., Kok, J. \& Venema, G. (1985). Construction of cloning, promoter-screening, and terminatorscreening shuttle vector for Bacillus subtilis and Streptococcus lactis. Appl Environ Microbiol 50, 540-542.

van der Vossen, J. M. B. M., van der Lelie, D. \& Venema, G. (1987). Isolation and characterization of Streptococcus cremoris Wg2-specific promoters. Appl Environ Microbiol 53, 2452-2457.

Worobo, R. W., van Belkum, M. J., Sailer, M., Roy, K. L., Vederas, J. C. \& Stiles, M. E. (1995). A signal peptide secretion-dependent bacteriocin from Carnobacterium divergens. J Bacteriol 177, 3143-3149.

Zhang, L. H., Fath, M. J., Tai, P. C. \& Kolter, R. (1995). Genetic analysis of the colicin V secretion pathway. Genetics 141, 25-32.

Received 26 February 1998; revised 15 June 1998; accepted 19 June 1998. 